\title{
Influence of Soil on Population Distribution
}

\author{
Talib Rayyis Ahmed ${ }^{1}$, Dhafyer Ibrahim Taha ${ }^{2}$ \\ ${ }^{1,2}$ Tikrit University, College of Education for Humanities
}

\begin{abstract}
Population distribution on the earth surface is determined by physical factors includes altitude and latitude, relief, climate, soils, vegetation, water and location of mineral and energy resources. Soil is one of the main physical factors that affect the distribution of the population. The quality of soils exerts an undeniable influence on the distribution of world population. Thus, the main objective of this paper is toaims to provide a review of the literature on theeffect of soil on population distribution. In addition, this paper elucidates and describes the significance of impact of soil on population distribution. This paper highlights several important issues related to impact of soil on population distribution which is not widely discussed among researchers. The current study provides theoretical evidence for the soil as an essential factor affect to population distribution.
\end{abstract}

Keywords: Soil, Population Distribution, Physical Factors

\section{Introduction}

The world's population has doubled since 1960 (Hern, 1999). Currently, the developing world accounts for about $95 \%$ of the population growth with Africa as the world's fastest growing continent (Hartemink, 2007). The growing population has many implications but most of all it requires an increase in agricultural production to meet food demand.
Soil science has a long tradition of considering the growth in food production in relation to the increasing human population (Pimentel, Huang, Cordova, \& Pimentel, 1997). Nowadays, some of the most fertile soils are found in the most densely populated spaces on the planet, which is shown in the following map.

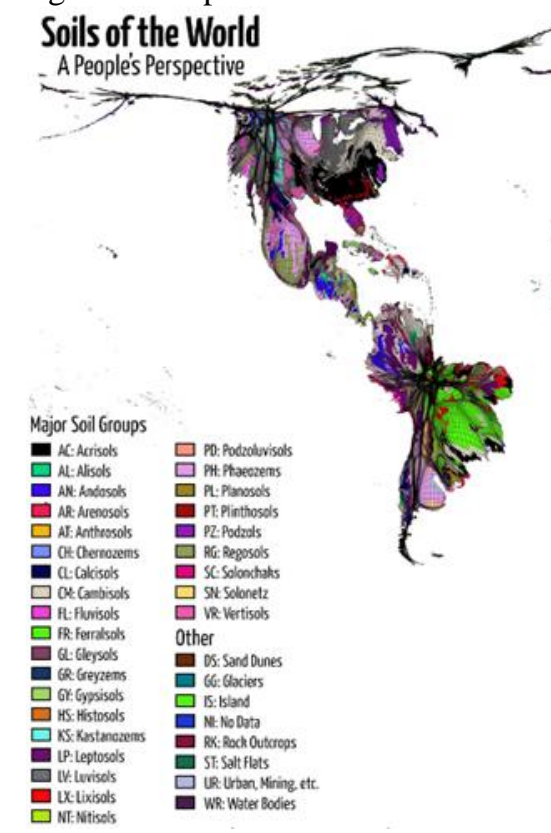

Source: FAO World Soil Database (2009)

Soil makes up the "thin" layer of the earth where we live. Soil structure holds a vital, but often overlooked role in sustainable food production and the population distribution (Bronick, \& Lal, 2005). Population distribution on the earth surface is determined by physical factors alone, for within the broad framework of physical attractions and constraints, cultural factors strongly influence the way mankind is distributed over the earth (Hornby and Jones, 1993). Thus, apart from physical factors, numerous social, demographic, economic, political and historical factors affect population distribution.

These factors operate not in isolation but in combination with each other. One cannot, therefore, isolate the influence of any one factor on population distribution(MitaliVerma,
2015). Further, the interplay between these determinants is generally very complex. The primary task of a population geographer, therefore, is to explain the irregularities in population distribution in terms of the influences of soil element as an integral part of a dynamic process (Clarke, 1972).

\section{Literature Review}

Population distribution and its growth are very crucial for any developed or developing region because land use pattern changes drastically with the increasing population. The population distribution patterns are determine by physical factors alone, for within broad framework of physical attractions and constraints cultural factors strongly influence

Volume 5 Issue 6, June 2016 www.ijsr.net 


\section{International Journal of Science and Research (IJSR) \\ ISSN (Online): 2319-7064 \\ Index Copernicus Value (2013): 6.14 | Impact Factor (2015): 6.391}

the pattern of distribution (Horneby and Jones, 1980). Soil structure exerts important effects on the environment and the edaphic conditions (Bronick, 2005). With increases in population and urbanization, it is important to identify methods to enhance food production while maintaining environmental quality.

In the existing literature a number of pertinent studies were identified. For instance,Bronick (2011) studied the Soil structure exerts important influences on the edaphic conditions and the environment. The findings of their study indicated that the Soil structure can be significantly modified through management practices and environmental changes. As well as this study were provided illustrations to Practices that increase productivity and decrease soil disruption enhance aggregation and structural development.Six, Paustian, Elliott, and Combrink, (2000) investigated the effect of cultivation intensity on aggregate distribution. The study revealed that increasing cultivation intensity leads to a loss of C-rich macro aggregates and an increase of Cdepleted micro aggregates in soils that express aggregate hierarchy.Drechsel, Gyiele, Kunze, and Cofie, (2001) examined the population density and soil nutrient depletion in sub-Saharan Africa. The study's findings indicated there is a significant relationship between population pressure, reduced fallow periods and soil nutrient depletion (including erosion), indicating a generally unsustainable dynamism between population, agriculture and environment. This review collates and synthesizes available information on soil and its dynamics in relation to population distribution. The overall effect of soil on population distribution is not very well understood.

In summary, there is lack of literature examining the effect of soil on population distribution. Therefore, this study extends the past studies through the examination of the new aspects which is important issues of soil effectiveness on population distribution.

\section{Population Distribution}

The word population can be used in some different ways, for instance, might refer to a collection of plants or animals as a population, whereas a geographer would be more likely to confine his use of the word to collections of human beings (Hornby et al., 1980). Population studies concern with the size of the population and its characteristics (Kumar, 2016). Along with this population studies also concern with the how population is distributed in various spatial divisions and the changes that occur in the patterns of population distribution of the decades. The importance of population distribution studies by its spatial pattern becomes evident when it is realized that small heavily populated areas exist near virtually uninhabited or sparsely inhabited areas (Bhende\&Kanitkar, 1993).

The study of population and its various aspects, such as population fertility, growth, distribution etc., has often been made somewhat in isolation, as being something purely distinct from other studies (Kayastha, 1998). The study of population distribution concerned with matters like, how the people are distributed, what is the nature of changes in population distribution, to find out the proportion of population living in advanced urban industrial areas, newly developing out growing urban industrial areas and rural areas and the ways in which changes are taking place in each category(Kumar, 2016).

\section{Soil Influence on Population Distribution}

Soil exerts important influences on the population distribution (MitaliVerma, 2015). Therefore, with increases in population and urbanization, it is important to identify effectiveness of soil on population distribution.

Physical factors that impact on the population distribution include altitude and latitude, climate,relief, soils, geographical location etc. (Kladivko, 2001; Anil Bose, 2013; MitaliVerma, 2015). It is important to note that majority of the physical factors are impacton population distribution indirectly by climatic conditions. The influences of soil on population distribution cannot be separated from one another. The quality of soils exerts undeniable impacts on the distribution of world population (MitaliVerma, 2015). Together andosols and fertile alluvial and deltaic soils seem to support dense populations (Veena, 2009). Thus, most of the major concentrations of populations in the world are located in the river valleys and deltas.Great civilizations of the world have almost invariably flourished on good fertile alluvial soils(Dhillon, 2004). Similarly, the chernozems of steppe grasslands and rich volcanic soils can support dense populationMitaliVerma, 2015).On the other hand, the leached soils of temperate lands, the pod sols, which are very poor in terms of fertility, can support only a sparse population. In Canada, for instance, marked difference can be noticed in population concentration between areas of clayey soils and pod sol soils(MitaliVerma, 2015).

It is important to note that the impact of soils cannot be viewed in isolation, that is, soils effect on the population distribution in association with other physical characteristics, mainly climate. Moreover, progress in technology can alter the effectiveness of soil types on population concentration to a greater extent (Falkenmark, \&Widstrand, 1992). Application of modern technologies during the recent times has greatly enhanced the profitability of cultivation in many areas of the world, which was hitherto not suitable for cultivation.Such areas have, thus, attracted population during the recent past. In association with climatic conditions, varying soil types give rise to variety of vegetation cover on the earth surface. These, in turn, provide contrasting environment for a variety of agricultural activities, and hence, lead to different population density. Tropical forests, savanna, tundra and taiga provide different media for human occupation and concentration.

\section{Conclusion}

Soil type holds a vital, but often overlooked role in population distribution. Progress in technology can alter the effectiveness of soil types on population concentration to a greater extent. This paper identified the influences of soil on population distribution as a one of physical factors. The paper examined issues related to the distribution of population of the decades. The study found the soil factor is strongly influence the pattern of distribution of population

\section{Volume 5 Issue 6, June 2016 www.ijsr.net}




\section{International Journal of Science and Research (IJSR) \\ ISSN (Online): 2319-7064}

Index Copernicus Value (2013): 6.14 | Impact Factor (2015): 6.391

(i.e. the quality of soils exerts undeniable influences on the distribution of world population).

\section{References}

[1] Anil Bose (2013) Factors Responsible for Uneven Distribution of Population in India

[2] Bhende and Kanitkar (1993).Principles of Population Studies, Himalaya Publishing House, India, 335.

[3] Bronick, C. J., \& Lal, R. (2005). Soil structure and management: a review.Geoderma, 124(1), 322.Hartemink, A. E. (2007). Soil science, population growth and food production: some historical developments. In Advances in Integrated Soil Fertility Management in sub-Saharan Africa: Challenges and Opportunities (pp. 85-97). Springer Netherlands.

[4] Clarke, J. I. (1972 )Population Geography, Pergamon Press, Oxford

[5] Dhillon, S. S. (2004). Agricultural Geography.Tata McGraw-Hill Education.

[6] Drechsel, P., Gyiele, L., Kunze, D., \&Cofie, O. (2001).Population density, soil nutrient depletion, and economic growth in sub-Saharan Africa.Ecological economics, 38(2), 251-258.

[7] Falkenmark, M., \&Widstrand, C. (1992). Population and water resources: a delicate balance. Population bulletin, 47(3), 1-36.

[8] Hern, W. M. (1999). How many times has the human population doubled? Comparisons with cancer. Population and Environment, 21(1), 59-80.

[9] Hornby, W.F., M. Jones 1993. An Introduction to Population Geography. Cambridge: Cambridge University Press.

[10] Hornby, W. F and Jones, W. (1980): An Introduction to Population Geography, Cambridge University, Press, Cambridge, p.20.

[11] Kayastha S.L. (1998). Geography of Population Selected Essay, Rawat Publications, Jaipur and New Delhi, 12.

[12] Kladivko, E. J. (2001). Tillage systems and soil ecology. Soil and Tillage Research, 61(1), 61-76.

[13] Kumar, D. (2016) Assessment of Population Dynamics Using Geographical Information System in Faridabad District, India, International Research Journal of Earth Sciences, Vol. 4(2), 1-8, February (2016)

[14] MitaliVerma (2015) Factors that Affects Population Distribution,

YourArticleLibrary.comhttp://www.yourarticlelibrary.c om/population-geography/factors-that-affectspopulation-distribution/43092/

[15] Pimentel, D., Huang, X., Cordova, A., \& Pimentel, M. (1997).Impact of population growth on food supplies and environment. Population \& Environment, 19(1), 914.

[16] Veena (2009)Understanding Earth Science, Discovery Publishing

Househttps://books.google.com.my/books?id=FKml3iA s_WUC\&pg=PA105\&lpg=PA105\&dq $=$ The+fertile + all uvial+and+deltaic+soils+can+support+dense+populatio ns\&source=bl\&ots=AQlvUZ0vRc\&sig=YRtY4P5EC5g kmGHFOBlc8Eu0byY\&hl=ar\&sa=X\&redir_esc $=y \# v=0$ nepage $\& \mathrm{q}=$ The $\% 20$ fertile $\% 20$ alluvial $\% 20$ and $\% 20$ deltai c\%20soils\%20can\%20support\%20dense\%20population $\mathrm{s} \& \mathrm{f}=$ false

[17] Six, J., Paustian, K., Elliott, E. T., \&Combrink, C. (2000).Soil structure and organic matter I. Distribution of aggregate-size classes and aggregate-associated carbon. Soil Science Society of America Journal, 64(2), 681-689.

Volume 5 Issue 6, June 2016 www.ijsr.net 